\title{
Over Vlaams-Nederlandse woordenboeken
}

\author{
STANISŁAW PRĘDOTA \\ University of Wroctaw \\ Katedra Filologii Niderlandzkiej \\ Uniwersytet Wrocławski \\ ul. Kuźnicza 21-22 \\ 50-138 Wrocław, Poland \\ alfa@predota.com
}

\section{On Flemish-Dutch Dictionaries}

\begin{abstract}
The contemporary Dutch language belongs to European multi-centered languages and has three variations: Dutch of the Kingdom of the Netherlands, Dutch in Northern Belgium, and Dutch in Surinam. There are differences among the above variations which mainly regard the pronunciation and lexicon. The Flemish and Surinam variations pose a great challenge, especially for the translators of the Flemish and Surinam literature. Similarly, they pose also a significant theoretical and practical problem for the authors of one and two-language dictionaries of the Dutch language. The contemporary lexicography attempts to register the differences which one can find between the standard of the Dutch language and: its Northern Belgium variation, as well as its Surinam variation. It needs to be noted that lexicographers so far have been paying much attention to lexical differences between Dutch of the Kingdom of the Netherlands and Dutch of the Northern Belgium. In this very paper there are described four printed Flemish-Dutch dictionaries and one online dictionary, we also characterize the Prisma Handwoordenboek Nederlands met onderscheid tussen het Belgisch-Nederlands en Nederlands-Nederlands met medewerking van W. Martin en W. Smedts.
\end{abstract}

Keywords: contemporary variations of the Dutch language; Flemish-Dutch dictionaries

Het moderne Nederlands behoort zoals bekend tot de pluricentrische Europese talen en heeft drie variëteiten: de Nederlandse in Nederland, de Noordbelgische in België en de Surinaams-Nederlandse in Suriname. Tussen deze variëteiten zijn er opvallende verschillen te constateren; vooral wat de uitspraak en de woordenschat betreft. Eigenaardigheden in de uitspraak vallen meteen op. 
Verschillen in de woordenschat kan men vaststellen bij de lectuur van Vlaamse of Surinaamse kranten of literatuur. Vroeger werden deze verschillen in het algemeen als incorrect gezien. Vanaf de jaren tachtig van de vorige eeuw is de attitude ten opzichte van de verschillen echter veranderd. Sindsdien worden ze namelijk als gelijkwaardige nationale varianten van het Nederlands beschouwd. Dit neemt echter niet weg dat ze een grote uitdaging zijn, voornamelijk voor vertalers van Vlaamse of Surinaamse schrijvers en ook voor degenen die Nederlands als vreemde taal leren. Tevens vormen ze een belangrijk theoretisch en praktisch probleem voor eentalige en bilinguale woordenboeken van het Nederlands. De moderne lexicografie tracht systematisch verschillen te registreren tussen de standaardvariëteit van het Nederlands en a) de Noordbelgische en b) de Surinaams-Nederlandse variëteit.

Het valt te benadrukken dat de lexicografen tot nu toe de meeste aandacht hebben besteed aan lexicale verschillen tussen het Nederlands in Nederland en in Noord-België. Op het ogenblik bestaan er reeds vier gedrukte en drie online woordenboeken Vlaams-Nederlands. Tot de gedrukte werken behoren:

1) Constant H. Peeters, Nederlandsche Taalgids. Woordenboek van Belgicismen, Antwerpen 1930, De Sikkel,

2) Walter de Clerck, Nijhoffs Zuidnederlands woordenboek, 's-Gravenhage, Antwerpen 1981, Martinus Nijhoff,

3) Ton van der Wouden, Verboden op het werk te komen. Klein woordenboek van Vlaamse taal- en andere eigenaardigheden, Enschede 1998, SIWU,

4) Peter Bakema, Patricia Defour, Marianne Jacobs, Sabine Lefever, Maurice Vandenbroek (red.), Vlaams-Nederlands woordenboek. Van ambetanteriek tot zwanzer, Antwerpen, Utrecht 2003, Staandaard Uitgeverij. Het Spectrum.

Bovendien is er ook nog het Prisma Handwoordenboek Nederlands met onderscheid tussen het Belgisch-Nederlands en Nederlands-Nederlands met medewerking van W. Martin en W. Smedts, Houten, Antwerpen 2012, Uitgeverij Uniboek. Het Spectrum. Later gaan we in het kort in op dit originele pionierswerk. Buiten beschouwing laten we hier echter kleine populaire uitgaven, bijv. Honderd taaie belgicismen (Hasselt 1968) en Nog honderd hardnekkige belgicismen (Haselt 1978) van Maarten van Nierop. De online woordenboeken zijn een recente ontwikkeling die de gedrukte woordenboeken kunnen completeren. Vermeldenswaardig is hier vooral Het Vlaams Woordenboek (http:/ / www.vlaamswoordenboek.be). Op 24 september 2013 bevat het al 18032 lemmata die door taalgebruikers zijn ingebracht.

In wat hier volgt presenteren we - in chronologische volgorde - lexicografische grondbeginselen en de macro- en microstructuur van de bovengenoemde gedrukte woordenboeken. Tevens valt het te benadrukken dat ze een bijzondere groep vormen in de lexicografie van het moderne Nederlands. 


\section{Nederlandsche Taalgids. Woordenboek van Belgicismen}

Het eerste woordenboek dat aan belgicismen is gewijd, d.w.z. "woorden, uitdrukkingen of constructies kenmerkend [...] voor het Nederlands in België en afwijkend [...] van de Nederlandse standaardtaal" (Geerst \& Heerstermans 1992: 307). Bedoeld is de Nederlandsche Taalgids. Woordenboek van Belgicismen van Constant H. Peeters, dat in 1930 is verschenen. Dit opus magnum heeft een door en door wetenschappelijk karakter. Imponerend is zijn omvang. Het telt 661 bladzijden en omvat naar onze voorzichtige schatting circa 7.500 lemmata. De Nederlandsche taalgids is puristisch van strekking waarbij het Nederlands in Nederland steeds als de norm heeft gegolden voor de samensteller. Daarin worden - in alfabetische volgorde - "de voornaamste Zuidnederlandsche afwijkingen van het algemeen Nederlandsch vermeld en toegelicht, de overeenkomstige woorden en uitdrukkingen in het algemeen Nederlandsch er tegenover gesteld" (Peeters 1930: XXII). In Voorafgaande Beschouwingen vinden we een door Peeters geïntroduceerde typologie van Zuidnederlandse bijzonderheden. Voor zover we het kunnen overzien is het de eerste dergelijke typologie. Daarbij heeft Peeters deze bijzonderheden in vier typen ingedeeld:
a) woorden en woordvormen, die in het Noorden verouderd zijn, of er nog in een of ander dialect voortleven,
b) andere die specifiek Vlaamsch zijn,
c) woorden die in ' $t$ Zuiden een begripswijzinging hebben ondergaan of althans tegenwoordig een geheel andere betekenis hebben dan in het Noorden,
d) woorden die het Zuidnederlandsch aan het Fransch heeft ontleend

(Constant H. Peeters 1930: XVII)

Bovendien onderscheidt Peeters nog twee soorten afkeurenswaardige barbarismen: gallicismen en germanismen.

Elke pagina van de Nederlandsche taalgids is in vier kolommen ingedeeld die de volgende opschriften hebben: Belgicismen, Toelichting, Algemeen Nederlandsch, Opmerkingen. Drie onderhavige voorbeelden: schepen, schoon en kuisen, zullen het verduidelijken.

Tabel 1. Schepen, p. 406

\begin{tabular}{|c|c|c|c|}
\hline Belgicismen & Toelichting & $\begin{array}{c}\text { Algemeen } \\
\text { Nederlandsch }\end{array}$ & Opmerkingen \\
\hline $\begin{array}{l}\text { Schepen, } \\
\text { schepene. }\end{array}$ & $\begin{array}{l}\text { Algemeen in Zuid-Nederland, } \\
\text { in de volkstaal meestal schepene, } \\
\text { hetgeen bij Vits, } 370 \text {, en bij } \\
\text { Lomb. } 48 /(74) \text {, wordt afgekeurd } \\
\text { voor schepen. }\end{array}$ & $\begin{array}{l}\text { Wethouder } \\
\text { (in Noord- } \\
\text { Nederland), } \\
\text { schepen (in } \\
\text { België) }\end{array}$ & $\begin{array}{l}\text { Verc., Etym. Wdb. - J. van } \\
\text { Vlaanderen, I, 56. - Woorden } \\
\text { en Uitdrukkingen, } 101 . \\
\text { - Kuipers. - Van Dale. - } \\
\text { Koenen. }\end{array}$ \\
\hline
\end{tabular}


Tabel 2. Schoon, p. 408

\begin{tabular}{|c|c|c|c|}
\hline Belgicismen & Toelichting & Algemeen Nederlandsch & Opmerkingen \\
\hline $\begin{array}{l}\text { Schoon, } \\
\text { Een schoone vrouw } \\
\text { met schoone oogen, } \\
\text { schoon haar. Dat is niet } \\
\text { schoon van } \mathrm{u} \text {. } \\
\text { Op een schoone dag. } \\
\text { Men heeft schoon } \\
\text { te zeggen [...] Hij } \\
\text { had zich schoon met } \\
\text { wilskracht te stalen } \\
\text { tegen de emotie } \\
\text { [...] Ik had schoon } \\
\text { commandos te geven, } \\
\text { mijne piketmannen } \\
\text { vielen mee aan 't } \\
\text { drinken. Simons, } 43 \text {. }\end{array}$ & $\begin{array}{l}\text { Bij V. Dale als } \\
\text { algemeen Nederlands } \\
\text { opgegeven; dit is in } \\
\text { overeenstemming met } \\
\text { de Zuidnederlandse } \\
\text { spreektaal. } \\
\text { Zuidnederlands } \\
\text { taalgebruik. Gewoon } \\
\text { gebruikelijk, ook in } \\
\text { de Zuidnederlandse } \\
\text { spreektaal, voor: op } \\
\text { zekeren dag; vgl. Frans } \\
\text { un beau jour. } \\
\text { Gall. avoir beau, gevolgd } \\
\text { door een onbepaalde } \\
\text { wijs, Broeckaert, 13, gaf } \\
\text { op ter verbetering van } \\
\text { den eersten zin: "Men } \\
\text { heeft wel, of goed, te } \\
\text { zeggen”; dit is echter } \\
\text { ook een belgicisme. } \\
\text { Naar eisch werd het } \\
\text { gallicisme verbeterd } \\
\text { bij D.V., 173, alwaar } \\
\text { men verder leest: } \\
\text { “Slechts in een geval } \\
\text { gebruikt het Nederlands } \\
\text { eene constructie, die } \\
\text { eenigszins met de } \\
\text { Fransche overeenkomt: } \\
\text { voor vous avez beau dire } \\
\text { namelijk zegt men in } \\
\text { Noord-Nederland gij } \\
\text { hebt wel te zeggen, } \\
\text { in Zuid-Nederland, } \\
\text { althans in Gent: gij } \\
\text { hebt wel te zeggen; gij } \\
\text { hebt wel te zeggen” Zie } \\
\text { verder Wand, 178; vgl. } \\
\text { ook D.B., 54-55, en V } \\
\text { G., I. 136). Algemeen } \\
\text { in de Zuidnederlandse } \\
\text { volkstaal, voor: door } \\
\text { vleierij iemands gunst } \\
\text { trachten te herwinnen. }\end{array}$ & $\begin{array}{l}\text { Een mooie vrouw met } \\
\text { mooie oogen, mooi haar. } \\
\text { Dat is niet mooi van je. } \\
\text { Op een goeden dag, op } \\
\text { een mooien dag. } \\
\text { Wat men ook moge } \\
\text { zeggen [...] } \\
\text { Hoe hij zich ook met } \\
\text { wilskracht staalde tegen } \\
\text { de emotie [...] } \\
\text { Al gaf ik commando's, } \\
\text { toch begonnen de } \\
\text { mannen van mijn piket } \\
\text { mee te drinken. }\end{array}$ & $\begin{array}{l}\text { Dit is vooral Nnd. } \\
\text { taalgebruik. In } \\
\text { de betekenis van } \\
\text { rein, zuiver, het } \\
\text { tegendeel van vuil, } \\
\text { bezigt men ook in } \\
\text { Noord-Nederland } \\
\text { alleen schoon, } \\
\text { bijv. een schoone } \\
\text { handdoek, een } \\
\text { schoon hemd, een } \\
\text { schoone lepel, } \\
\text { schoon water. } \\
\text { Dubois, 20: J' } \\
\text { ai beau sonner, } \\
\text { on n'ouvre pas. } \\
\text { Tevergeefs bel } \\
\text { ik, men doet niet } \\
\text { open. - Vous avez } \\
\text { beau les appeler, } \\
\text { ils ne viendront } \\
\text { pas. Het zal niet } \\
\text { helpen, of gij hen } \\
\text { roept, zij zullen } \\
\text { niet komen. - J' eus } \\
\text { beau lui parler de } \\
\text { ses parents rien n'y } \\
\text { fit. Of ik hem al van } \\
\text { zijne ouders sprak, } \\
\text { niets hielp. } \\
\text { Betsy, Vrij en } \\
\text { blij, 60: De arme } \\
\text { Lodewijk had mooi } \\
\text { klagen, dat het } \\
\text { regeeren op die } \\
\text { wijze onmogelijk } \\
\text { was [...] Napoleon } \\
\text { was onverbiddelijk. } \\
\text { Zie ook op het w. } \\
\text { goed. }\end{array}$ \\
\hline
\end{tabular}


Tabel 3. Kuischen, p. 267

\begin{tabular}{llll}
\hline \multicolumn{1}{c}{ Belgicismen } & \multicolumn{1}{c}{ Toelichting } & \multicolumn{1}{c}{ Algemeen Nederlandsch } & \multicolumn{1}{c}{ Opmerkingen } \\
\hline Kuischen. & Alg. in Z.-N., ook & Het huis schoonmaken. & Verc. 150. - Kuipers. - V. \\
$\begin{array}{l}\text { Het huis } \\
\text { kuischen. De }\end{array}$ & nog gewestelijk & De stallen reinigen. & Dale. - Koenen. - Gr. Wdb., \\
stallen kuischen. & Z. van den & Het zilverwerk poetsen. & VIII, 526. \\
Simon, 45. Het & Moerdijk, voor: & Al wrijvend aan zijn vuile & Alg. Ndl. kuischen \\
zilverwerk & schoonmaken, & & - zuiveren van \\
kuischen. Al & reinigen, zuiveren, & verkeerdheden, inz. van taal \\
kuischend aan & van vuil ontdoen; & Zijn glas uitdrinken. & en stijl: verbeteren, b.v. in \\
zijn vuile broek. & Meijers Wsch. & & kuischen; vgl. gekuischte \\
$\begin{array}{l}\text { Simons, } 96 . \\
\text { Zijn glas }\end{array}$ & (1745): kuisschen, & & smaak. \\
kuischen. & schoon maken, & & \\
\hline
\end{tabular}

C. H. Peeters (1880-1951) was - naar het schijnt - geen hoogleraar aan een Nederlandse of Belgische universiteit. Kenmerkend voor zijn woordenboek is echter een grondige kennis van de geschiedenis van het Nederlands en van de Nederlandse dialectologie. De door hem geschreven woordenboekartikelen lijken vaak op kleine woordmonografieën in eerste aanleg. Indrukwekkend is de hoeveelheid gedetailleerde filologische gegevens die hij daarbij verstrekt. Men kan er echter over twisten of die informatie inderdaad noodzakelijk en bruikbaar is voor doorsneegebruikers van dit woordenboek. Door Peeters wordt beklemtoond dat zijn compendium vooral is bedoeld voor leerkrachten, scholieren en studenten in Noord-België. Uit de inleiding blijkt duidelijk dat de Nederlandsche taalgids gewaardeerd werd door de toenmalige Belgische en Nederlandse professoren in de neerlandistiek. Vermoedelijk heeft het ook in een behoefte voorzien want al drie jaar na de eerste druk is de tweede druk verschenen.

Vermeldenswaardig is nog het feit dat de Nederlandse linguïst P.C. Paardekooper (1920-2013) goed de waarde van de Nederlandsche Taalgids en de tekortkomingen ervan besefte. In het jaar 1963 heeft hij zijn ABN-gids uitgegeven die zich later in een grote populariteit verheugde en in 1996 de 12e uitgave haalde. Het was een gemoderniseerde, vereenvoudigde en sterk verkorte pocketboekversie van de Nederlandsche Taalgids van Constant H. Peeters.

\section{Nijhoffs Zuidnederlands woordenboek}

Nijhoffs Zuidnederlands woordenboek van Walter de Clerck is in 1981 uitgegeven. Uit de catalogus van de Koninklijke Bibliotheek in Den Haag blijkt dat de in 1944 geboren lexicograaf bovendien nog de Retrograde woordenlijst bij Nijhoffs 
Zuidnederlands woordenboek ('s-Gravenhage 1981) heeft gepubliceerd. Het is het meest uitgebreide populair-wetenschappelijke werk onder de hier te presenteren Vlaams-Nederlandse woordenboeken. Het omvat $854 \mathrm{blz}$. en telt in totaal 4780 hoofdingangen. Dit woordenboek is descriptief. Het wil helpen Zuidnederlandse teksten te begrijpen.

Woordenboekartikelen bestaan in de regel uit drie bestanddelen. Na het trefwoord in kwestie staan de grammaticale gegevens. Verder vindt men er talrijke bewijsplaatsen uit de Vlaamse pers en literatuur. De materiaalverzameling waarop De Clercks woordenboek steunt is indrukwekkend want ze omvat 80.000 bewijsplaatsen. Het valt daarbij te beklemtonen dat het excerpeerwerk verricht werd door Nederlanders. Een groot gedeelte van de bewijsplaatsen is gebaseerd op geschreven taal. Een belangrijke innovatie zijn hier echter de spreektaalwoorden die door een asterisk * zijn gekenmerkt, bijv.

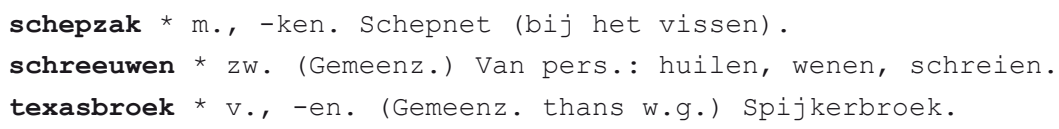

Daarbij steunt het spreektaalmateriaal namelijk op aantekeningen van radio- en televisieuitzendingen en ook nog op tijdens bezoeken genoteerde uitspraken.

Door W. de Clerck zijn slechts deze woorden in zijn woordenboek opgenomen die aan twee voorwaarden voldoen:

a) ze moeten in twee of meer provincies van België voorkomen,

b) ze mogen niet zuiver dialectisch zijn.

Hier presenteren we verklaringen en bewijsplaatsen van de Zuidnederlandse woorden schepen, schoon en kuisen.

\footnotetext{
schepen m, -en (Wdl.). (Belg.) Door de gemeenteraad uit zijn midden gekozen lid van het dagelijks bestuur van een gemeente; in Nederland: wethouder. - Daarnaast ook de vrouwelijk vorm schepene. Hij mocht tegen elven op het stadhuis zijn; hij is de schepen van onderwijs, hij hoopt nu natuurlijk burgemeester te worden, Van Aken 1965, p.144.

Je wordt vriendelijk uitgenodigd op het eerste bal van de burgemeester of op het zesde bal van de schepen van cultuur, Vrouw en Wereld dec. 1973, p. 40. Op deze dag gaan we onze burgemeester, schepenen en gemeenteraadsleden verkiezen in de nieuwe gemeenten die na de fusieoperatie ontstaan zijn, Vrouw en Wereld maart 1976, p. 6. Tenslotte zal een gezinsbeleid tot snellere concrete resultaten komen wanneer zulk beleid behoort tot de specifieke opdracht van een schepen, vandaar de noodzakelijkheid van een schepen van het gezin. Uit een informatiefolder. Boom sept. 1976.

R.V. is schepen van cultuur van de grootste stad van België. Gentenaar $22 / 5 / 77$. Burgemeester $V$. was verontschuldigd en het was schepen voor sport B. die C.H. op het gemeentehuis in de raadszaal mocht begroeten, Gazet van Antwerpen 16/9/1977.
} 
Namens het college van burgemeester en schepenen, Boom 2/6/1978. Ook o.a.: Buysse 1959, 124, Limburg 31/8/1976. Nieuwsblad 18/4/1977. Opmerking.: In de standaardtaal wel als historische term: stedelijk overheidspersoon, lid van het met bestuur en wetgeving, ten dele ook met rechtspraak belaste college. (p. 454).

Schoon bnw. en bijw. In Vl.-België nog zeer gewoon in versch. toep. die in de standaardt. niet meer voorkomen.

1. Van pers. en zaken: behaaglijk voor het oog of oor, van behaaglijk voorkomen; mooi, fraai; knap (van uiterlijk); prachtig enz. [...]

2. Een aangename indruk makend door het voorkomen, in verband met hoge kwaliteit of bruikbaarheid; van goede kwaliteit, van waarde, waardevol; van pers. bep. ; flink, knap; met het oog op maatschappelijke stand of zedelijke waarde: degelijk, fatsoenlijk. [...]

3. Van handelingen, uitingen of toestanden: wat ons zedelijk gevoel treft, verheven, loffelijk; soms bep.: bewonderenswaardig. [...]

4. Wat een aangename indruk maakt: aangenaam, behaaglijk; m.n. het weer e.d.; ook plezierig, merkwaardig; inz. in de verb. het schoonste van al; - als bijw. : op een aangename wijze, zoals men het graag heeft; vand.: beleefd, in. verb. als: iets schoon vragen, zeggen; keurig, volledig, in verb. als iets schoon uitleggen, vertellen. [...]

5. Gelegen komend; ook in verzwakte bet.: op een schone dag e.d., op een andere dag, op zekere dag; ook: ineens, plots. [...]

6. Gunstig, in versch. toep.: gunstige verwachtingen veroorlovend: een schone kans, gelegenheid; een gunstige voorstelling gevend: schone beloften, woorden e.d. ; - gij hebt schoon praten, klappen e.d., jij hebt mooi praten. $[\ldots]$

7. Van bedragen, een leeftijd e.d.: aanzienlijk, de moeite waard, niet te versmaden; een schoon pensioen hebben.

8. In de uitdr. het gat schoon hebben, vrij spel hebben, een goede gelegenheid hebben.

Opm.: In de standaardt. is schoon in de hierboven genoemde toep. zo goed als volledig verdrongen door mooi (en andere syn.), behalve in bijz. stijl of in ironische toep.; de belangrijkste uitzonderingen hierop zijn: in de bet. 1 wordt schoon wel van mooi onderscheiden als een hogere, zuiver esthetische kwaliteit; in de esthetica dus wel: de leer van het schone; in de bet. 2 kent de standaardt. wel de uitdr.: hoe later op de dag, hoe schoner volk; in de bet. 6 ook: de kans schoon zien, een gunstige gelegenheid ontdekken. In de standaardt. is de gewone bet. van schoon: zindelijk, vrij van vuil, pas gewassen, pas schoongemaakt; nog niet gebruikt enz. (p. 458 - 460).

Kuisen zw. (Trans.) Schoonmaken, poetsen, reinigen (in versch. toep.); soms bep.: (een tuin) van onkruid ontdoen, wieden; (water) zuiveren; (oude stenen) afbikken; - (gemeenz.) zijn glas kuisen, uitdrinken. [...]

opm.: In de standaardt. uitsl. in de bet.; zuiveren van verkeerdheden, thans inz. van taal en stijl gezegd, en dan vooral in de vorm van het verl. deelw. gekuist als bnw. (p. 240).

De verklaringen en bewijsplaatsen in het woordenboek van De Clerck zijn in de regel omvangrijker dan die in het woordenboek van Peeters. Opgenomen bewijsplaatsen zijn gebaseerd op literaire werken van de Vlaamse auteurs en op Vlaamse kranten. Zo ontbreken hier compleet de taalhistorische en 
dialectologische toelichtingen die zo typisch zijn voor de Nederlandsche Taalgids. Voor geïnteresseerde lezers zijn er echter nog vier aanhangsels. Daarin aanvullende informatie die Zuidnederlandse woorden betreft. Men vindt er

I. Lijst van vormvarianten,

II. Lijst van Franse leenwoorden,

III. Register van Woordenlijst-woorden,

IV. Synoniemenlijst.

\section{Verboden op het werk te komen. Klein woordenboek van Vlaamse en andere eigenaardigheden}

Verboden op het werk te komen. Klein woordenboek van Vlaamse en andere eigenaardigheden van Ton van der Wouden is in 1998 uitgegeven. Het is een vrij bescheiden éénmanswerk van een populair-wetenschappelijk en descriptief karakter. Het is het kleinst van de hier te presenteren woordenboeken. In totaal telt het $143 \mathrm{blz}$. en het omvat circa 1.300 woordenboekartikelen. De samensteller ervan is een neerlandicus die vroeger verbonden was aan de universiteit in Groningen en later die in Leiden. Hij is gefascineerd door bijzonderheden van het Belgisch Nederlands. Dit woordenboek is het resulaat van zijn jarenlange opsporingen tijdens zijn talrijke verblijven in Noord-België. Als bronnen gebruikte hij ook Vlaamse kranten en uitzendingen van de BRT en VTM. Als trefwoorden heeft hij niet alleen inhouds- en functiewoorden opgenomen. Tevens heeft hij verschillen in aanmerking genomen die het gebruik van lidwoorden en voorzetsels en de woordvolgorde betreffen, bijv.

het voorzetsel aan (aan de prijs van 175 frank), (p. 7),

het voegwoord eens (rusten doe ik wel, eens ik gestorven ben), (p. 7),

het bijwoord toch dat helemaal achteraan kan staan (in België toch), (p. 7).

De woordenboekartikelen in Verboden op het werk te komen zijn niet uitgebreid en in de regel bestaan ze uit drie bestanddelen. Na het lemma staat er een beknopte definitie. Daarop volgen er een of meer bewijsplaatsen. We illustreren het met de trefwoorden schepen, schoon en kuisen.

\footnotetext{
Schepen <zn> 'wethouder'; alle pogingen om met de bevoegde schepen te spreken, zijn tot nu toe mislukt (LN); Monika van Paemel. Zij schreef over een schepen in Vermaledijde Vaders. Dit werd bij Meulenhoff veranderd in wethouder. Er loopt in heel Vlaanderen geen enkele wethouder rond, wel honderden schepenen (VV); het schepencollege, officieel college van burgemeester en schepenen, is vergelijkbaar met het Nederlandse b en w, 'burgemeester en wethouders': het schepencollege kan zijn toestemming afhankelijk maken van een reeks omstandigheden, zoals de nabijheid van bejaardentehuizen of natuurreservaten (DM). [p. 112].
} 
Schoon <bn> 'mooi': Ivan Heylen zong hé, schoon wijveken, ge weet dat ik u geren zie 'hé, mooi meisje, je weet dat ik van je houd'; ik vond het schoon van hem (DM); 'het was een moeilijke bevalling, maar het zal een schone baby zijn' zo vatte Vlaanderens topartiest zijn dag samen (LN); dan zullen we in elk geval weer tijd hebben voor 't schoon leven (TK); kunstverzamelingen heten Museum voor Schone Kunsten, en ook wat in Nederland Kunstacademie heet, staat in Vlaanderen bekend als Academie voor Schoone Kunsten [...] [p. 113].

Kuisen 〈wW> 'schoonmaken': gekuiste bloemkool (adv. DM); Yucca groet Zaventem en de wereld. Na een zwangerschap van 5 maanden vol getimmer, geverf en gekuis, ziet op 30 april 1996 een nieuwe boreling het levenslicht: Jeugdhuis Yucca (BIJ); als er is iets omgaat dan kan men de gemorste vloeistof opkuisen: samen met een bediende kuiste ik het goedje op (LN); opkuisen is ook 'opruimen, schoonmaken [...]: een echte aanrader, dat opkuisen na een fuif! (TK) [...]. [p. 82].

Bovendien zijn talrijke woordenboekartikelen van originele foto's voorzien die Van der Wouden heeft toegevoegd ter illustratie van bepaalde Noordbelgische bijzonderheden.

\section{Vlaams-Nederlands woordenboek. Van ambetanterik tot zwanzer}

Het Vlaams-Nederlands woordenboek. Van ambetanterik tot zwanzer is samengesteld door Peter Bakema, Patricia Defour, Marianne Jacobs, Sabine Lefever en Maurice Vandenbroek. (De bekendste van deze samenstellers is de Nederlandse taalkundige Peter Bakema). Dit woordenboek heeft ook een populairwetenschappelijk karakter en is descriptief van strekking. Qua omvang is het bijna drie keer groter dan Verboden op het werk te komen van Ton van der Wouden. Het telt 395 blz. en omvat naar schatting circa 5.300 lemmata. Woordenboekartikelen hebben in de regel drie of vier componenten. Na het lemma in kwestie vindt men de grammaticale gegevens. Daarop volgen: een betekenisverklaring en een of meer bewijsplaatsen die zijn ontleend aan Vlaamse kranten of literaire werken van de Vlaamse auteurs. Ter illustratie gebruiken we de lemmata schepen, schoon en kuisen.

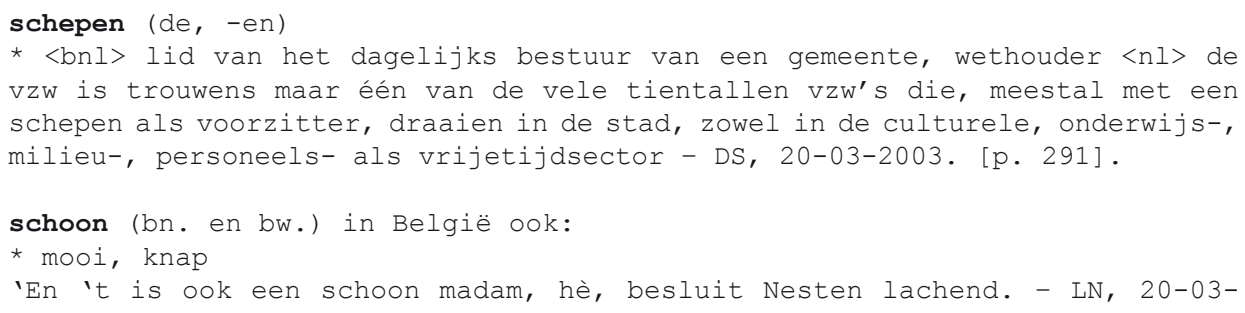


2003. Denert hield - in gezelschap van medeactievoerders - woord en legde zich in z'n schoon kostuum en met tricolore sjerp voor werftransporten. LN, 19-03.2003.

* flink, degelijk, fatsoenlijk

Zaterdagnamidddag start dan een marathon-live-uitzending vanuit de studio, met artiesten als Zornik, Kate Ryan en Milk Inc, maar ook politici, sportlui en ander schoon volk komen op bezoek. - DS, 20-03-2003.

* aangenaam, plezierig, gunstig. [p. 293].

kuisen (kuiste, gekuist)

schoonmaken, poetsen, reinigen

Vroeger verkocht men mosselen tout court. Er was alleeen een prijsverschil tussen gekuiste en ongekuiste mosselen. - Humo, 12-08-2002. [p. 173].

Een belangrijkse innovatie zijn talrijke Zuidnederlandse fraseologismen die in een reeks woordenboekartikelen zijn opgenomen. Ze zijn voorzien van Standaardnederlandse equivalenten of van korte verklaringen en in sommige gevallen ook van bewijsplaatsen. Bovendien vinden we in vele woordenboekartikelen ook originele foto's of afbeeldingen. Daartoe behoren met name advertenties, krantenkoppen en titels van krantenartikelen, bijv.

- beenhouwer gevraagd

- instapklare bel-etage

- $\quad$ eetplaats te koop

- dynamische florist(e)

- Antwerps college ziet geen graten in aankoopgedrag

- jobstudenten ontslagen door slecht weer

- computerbureel in massieve kerselaar

- controle op mazoettanks is lek

- politie doet nazicht

- gevraagd: voor onmiddellijke indiensttreding: ontvlekker voor nieuwkuis

- opkuis nucleaire sites kost 5,6 miljard euro

- Agalev wil niet de 'schotelvod' van de maatschappij zijn

- $\quad$ rustig uitbollen op het einde van de loopbaan.

\section{Prisma Handwoordenboek Nederlands met onderscheid tussen het Belgisch-Nederlands en Nederlands-Nederlands}

Het Prisma Handwoordenboek Nederlands met onderscheid tussen het BelgischNederlands en Nederlands-Nederlands met medewerking van W. Martin en $W$. Smedts betekent een belangrijk keerpunt in de Nederlandse lexicografie. Het is het eerste Nederlandse woordenboek waarin niet alleen Zuidnederlandse, 
maar ook Noordnederlandse lexicale bijzonderheden zijn opgenomen. Aan de totstandkoming ervan hebben twee bekende Vlaamse taalkundigen, W. Martin (VU Amsterdam) en W. Smedts (KU Leuven), meegewerkt. De BelgischNederlandse lemmata zijn gebaseerd op het Referentiebestand Belgisch Nederlands (RBBN) dat de beide lexicografen hebben samengesteld. Deze database omvat circa 4.000 woorden en uitdrukkingen die kenmerkend zijn voor het Nederlands in België.

Het handwoordenboek telt $1535 \mathrm{blz}$. en omvat circa 70.000 trefwoorden. Na het lemma in kwestie volgen de grammaticale gegevens en daarna de definitie. Ter illustratie gebruiken we hier de trefwoorden schepen, schoon en kuisen.

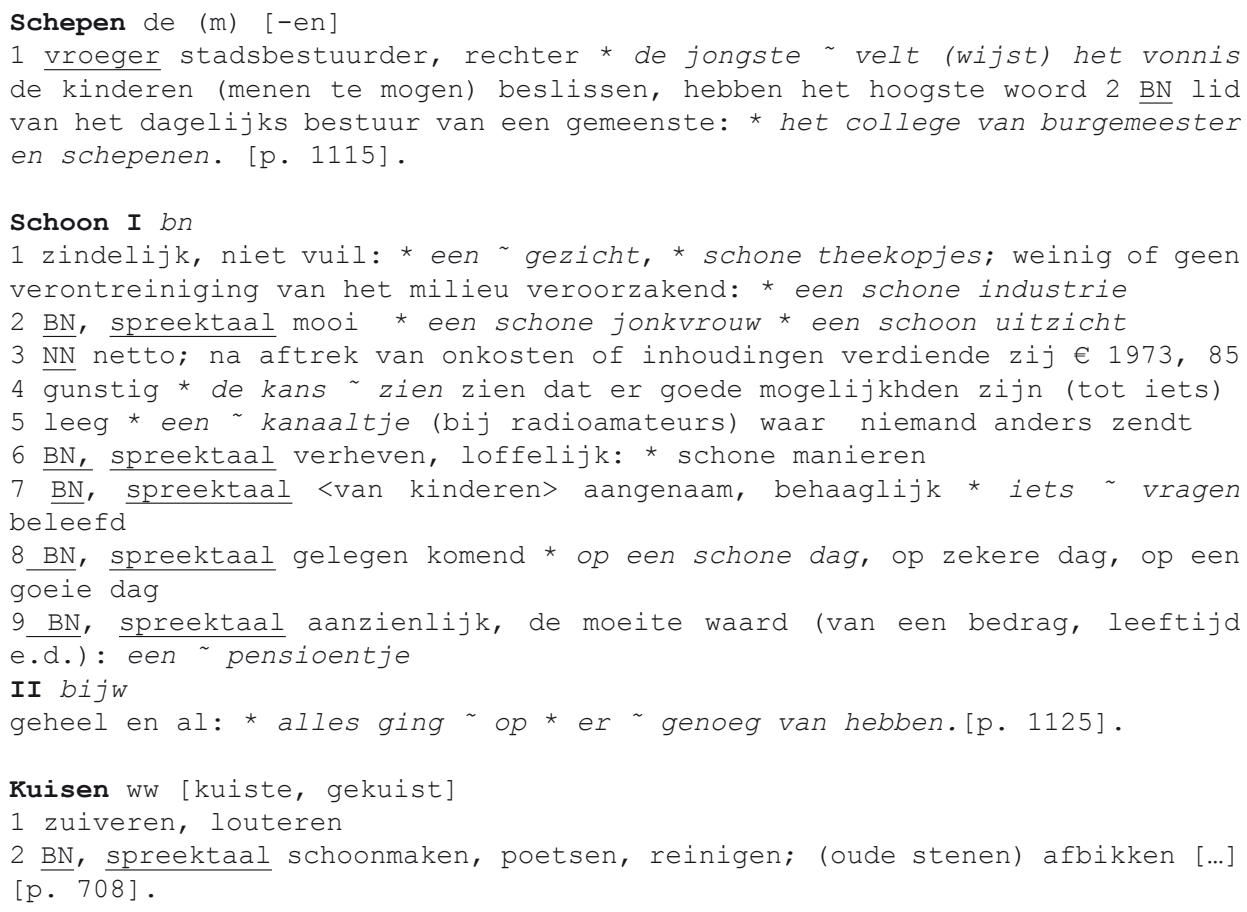

De eerste door W. Martin en W. Smedts geïntroduceerde innovatie bestaat daarin dat zij een originele typologie van lexicale Belgisch-Nederlandse bijzonderheden hebben voorgelegd. In tegenstelling tot de indeling van Peeters uit het jaar 1930 is ze op exacte criteria gebaseerd. Daarbij zijn deze bijzonderheden in vier typen ingedeeld en van speciale labels voorzien. In wat hier volgt presenteren we deze indeling.

Type 1. Woorden en uitdrukkingen die alleen in België worden gebruikt en die daar algemeen gebruikelijk zijn, krijgen het label $\underline{\mathrm{BN}}$. Voorbeelden: 
hof van assisen - gerechtshof met jury voor zware misdrijven bedrijfsrevisor - onafhankelijk controleur van de boekhouding van een bedrijf papierslag - inzameling [door jeugdbeweging] van oud papier voor een goed doel de Lange Wapper - (fig.) naam van een geplande tuikabelbrug over de dokken in Antwerpen kerststronk - speciaal kerstgebak in de vorm van een stuk boomstam. Type 2. Woorden en uitdrukkingen die alleen in België worden gebruikt, maar die een gebruiksbeperking vertonen, krijgen het label $\underline{\mathrm{BN}}$ gevolgd door een beperkend label. Hieronder vallen woorden die vooral of uitsluitend in gesproken of in geschreven taal voorkomen, die tot een bepaald domein behoren of die vooral door een bepaalde sociale groep worden gebruikt. Voorbeelden:

$\underline{\mathrm{BN}}$, spreektaal - foor, luieriken, mottig (= niet lekker, onwel)

$\underline{\mathrm{BN}}$, vero - gegradueerde, vierklauwens, derven (= zich onthouden van)

$\underline{\mathrm{BN}}$, schrijftaal - spijts, gebeurlijk, veropenbaren

$\underline{\mathrm{BN}}, \underline{\mathrm{sp}}$ - provinciale, remonte, vlucht (= duivenwedstrijd)

Type 3. Woorden en uitdrukkingen die weliswaar typisch BelgischNederlands zijn, maar die een tegenhanger hebben die in Nederland gebruikelijk is én die eveneens in België voorkomt, krijgen het label $\underline{B N}$ ook. Dat label komt vrij vaak voor, omdat het gebruik van Nederlandse varianten decennialang in België sterk gepropageerd werd. Daardoor kennen en gebruiken heel wat Belgen naast het typisch BelgischNederlandse woord vaak ook het Nederlands-Nederlandse of het algemene equivalent. Het verschil met de eeste groep (de BN-woorden) is dat de Nederlands-Nederlandse tegenhanger daar niet bestaat of in België niet of nauwelijks bekend is.

$\begin{array}{ll}\text { oudercontact } \underline{\mathrm{BN} \text { ook }} & \text { - ouderavond } \\ \text { rondpunt } \underline{\mathrm{BN} \text { ook }} & \text { - rotonde } \\ \text { nota } \mathrm{BN} \text { ook } & \text { - aantekening, notitie } \\ \text { BN ook erg en weer } & \text { - heen en weer }\end{array}$

Type 4. Woorden en uitdrukkingen die oorspronkelijk BelgischNederlands zijn, maar die nu ook wel in Nederland worden gebruikt, krijgen het label vooral BN. Voorbeelden:

familienaam vooral BN

holebi vooral BN

plichtbewust vooral BN

kort op de bal spelen vooral BN
- achternaam

- homo, lesbienne of biseksueel

- plichtsgetrouw

- snel reageren (Martin en Smedts 2012: 6-7) 
De tweede belangrijke innovatie in het handwoordenboek van W. Martin en W. Smedts bestaat erin dat hier ook deze woorden gekenmerkt worden die typisch zijn voor het Nederlands in Nederland. Ze worden naar exacte criteria in vier typen ingedeeld. Deze typologie is echter niet parallel aan de indeling van Belgische bijzonderheden van het Nederlands. Voor Nederlandse bijzonderheden van het Nederlands bestaat echter nog geen database zoals het Referentiebestand Belgisch Nederlands. De beide lexicografen moesten dus intuïtief woorden en uitdrukkingen selecteren die karakteristiek zijn voor het Nederlands in Nederland.

Typ 1. Woorden en uitdrukkingen die alleen of in uitgesproken mate in Nederland worden gebruikt en die daar algemeen gebruikelijk zijn, krijgen het label $\mathrm{NN}$. Voorbeelden:

$\begin{array}{ll}\text { reflectant } & \text { - gegadigde }[\ldots] \text { voor een vacature } \\ \text { pakjesavond } & \text { - avond van } 5 \text { december, sinterklaasavond } \\ \text { stoethaspel } & \text { - onhandig persoon } \\ \text { steggelen } & \text { - kibbelen, ruziën; oneerlijk handelen } \\ \text { blij toe! } & \text { - gelukkig maar! } \\ \text { van haver tot gort } & \text { - tot in de bijzonderheden }\end{array}$

Typ 2. Woorden of uitdrukkingen die oorspronkelijk NederlandsNederlands zijn, maar die ook in België ingang vinden, krijgen het label vooral NN. Voorbeelden:

pittig - kernachtig; flink, stevig

destructiebedrijf - bedrijf dat zich bezighoudt met de destructie van dierlijk afval

foeteren - mopperen, schelden

gelijk - direct, meteen

Typ 3. Woorden en uitdrukkingen met een NN-label en vooral NNlabel die een gebruiksbeperking vertonen, krijgen na dat label nog het beperkende label. Voorbeelden:

NN. spreektaal - moppie, opzouten, jij-bak, ben je niet lekker?

NN. vero - schoelje, strengen, weshalve, voor de mast zitten

$\underline{N N}$. schertsend - kikkerland, slootwater, uitgevroten, helaas pindakaas

NN. jeugdtaal - mocro, doekoe, gaaf, heftig (= prachtig) vooral NN. spreektaal - oen, geheid, emmeren, van mij kan ze de boom in vooral NN. fig - sluitpost, dat is niet misselijk, sporen met (= passen bij)

Typ 4. Woorden en uitdrukkingen die een typisch NederlandsNederlands tegenhanger hebben naast een in het hele taalgebied gebruikelijke variant, krijgen het label $\underline{\mathrm{NN}}$ ook. Voorbeelden: 
boffer

als de bliksem
- NN ook bofkont

- $\underline{N N}$ ook als de gesmeerde bliksem

van de ene dag in de andere leven - $\underline{\mathrm{NN}}$ ook bij de dag leven

het er levend van afbrengen
- NN ook er het leven afbrengen. (Martin en Smedts 2012: 7-8)

Het aantal woorden en uitdrukkingen die typisch zijn voor het Nederlands in Nederland werd echter niet vermeld. Tevens zou het hier vermeld moeten worden dat de interne stratificatie van het Belgisch Nederlands aan bod komt reeds vanaf de 13de editie van de Dikke Van Dale (1999) aan de hand van labels. ${ }^{1}$

\section{Besluit}

Bij wijze van een kort besluit willen we hier nog op drie bijzonderheden van de Vlaamse-Nederlandse woordenboeken verwijzen.

a) Het woordenboek van Peeters is nog prescriptief aangelegd. De werken van De Clerck, van Van der Wouden en van Bakema zijn al descriptief.

b) Het woordenboek van W. Martin en W. Smedts behandelt zowel Zuidnederlandse als ook Noordnederlandse lexicale bijzonderheden.

c) Een bijzondere categorie vormen de online woordenboeken, vooral Het Vlaams woordenboek. Ze zijn een interessante ontwikkeling en kunnen de gedrukte woordenboeken completeren.

\section{Literatuur}

Bakema, Peter, Defour Patricia, Jacobs Marianne, Lefever Sabine, Vandenbroek Maurice, eds. 2003. Vlaams-Nederlands woordenboek. Van ambetanteriek tot zwanzer. Antwerpen: Standaard Uitgeverij; Utrecht: Het Spectrum.

Claes, Frans, Bakema Peter. 1995. A Bibliography of Dutch Dictionaries. Tübingen: Max Niemeyer Verlag.

Clerck, Walter de. 1981. Nijhoffs Zuidnederlands woordenboek. 's-Gravenhage-Antwerpen: Martinus Nijhoff.

Geeraerts, D., Janssens D. 1982. Wegwijs in woordeboeken. Een kritisch overzicht van de lexicografie van het Nederlands. Assen: Van Gorcum.

Geerts, G., Heestermans H. 1992. Van Dale Groot Woordenboek der Nederlandse taal. Utrecht-Antwerpen: Van Dale Lexicografie.

Martin, Willy, Smedts Willy. 2012. Prisma Handwoordenboek Nederlands met onderscheid tussen het Belgisch-Nederlands en Nederlands-Nederlands. Houten: Uitgeverij Uniboek; Antwerpen: Het Spectrum.

\footnotetext{
${ }^{1}$ Voor deze opmerking dank ik hiermee één van de anonieme recensenten.
} 
Paardekooper, P.C. 1963. ABN-gids. Antwerpen, Amsterdam: Standaard-Boekhandel. Peeters, Constant H. 1930. Nederlandsche Taalgids. Woordenboek van Belgicismen. Antwerpen: De Sikkel.

Wouden, Ton van der. 1998. Verboden op het werk te komen: Klein woordenboek van Vlaamse taal- en andere eigenaardigheden. Enschede: SIWU. 